\title{
PUSAT INFORMASI PARIWISATA KABUPATEN SUMBA TENGAH BERBASIS WEBSITE
}

\author{
Alderbetus Umbu Janga1) \\ Junianto Tjahjo Darsono $\left.{ }^{2}\right)$ \\ Harianto Respati $\left.{ }^{3}\right)$ \\ Program Pascasarjana Universitas Merdeka Malang \\ Jl. Terusan Raya Dieng No.59 Malang
}

Korespondensi dengan Penulis:

Pascasarjana Unmer Malang: Telp: 0341-582881

\begin{abstract}
Technological developments rapidly growth such as the internet, it is time information management manual was gradually replaced by the information management that is technology. For it is necessary such as the design of information system of tourism in a web-based Central Sumba Regency. As for the purpose of this research is to help Central Sumba Regency Government to attract tourists visit through. In order to make all the content of the information contained on the web has the administration control panel to be able to do management, edit and delete data on tourism. Software developed in the preparation of this final Task using HTML (Hypertext Markup Language) which is the basic language for web scripting and client side that allows the display of information in the form of text, grafiks, and also to connectbetween the display Page (Hyperlink). In addition it is also used to program PHP and MySQL to create information systems be accurate. The end resulct of this research is produced a web-based application program that can give you an idea of the information system of tourism Central Sumba Regency that can display information about the profile of tourism.
\end{abstract}

Keywords: tourism, Website and information

Sejalan dengan perkembangan dunia komputer, internet telah menjadi hal yang sangat penting bagi masyarakat. Internet berperan pada berbagai bidang seperti bidang pariwisata dan kebudayaan. Pariwisata dan kebudayaan merupakan sektor potensial dan perlu mendapat perhatian dari pemerintah daerah untuk keberlangsungan pembangunan suatu daerah. Guna mencapai tujuan kepariwisataan diperlukan informasi 
tentang suatu daerah yang terdiri dari objek wisata yang menarik, sarana dan prasarana seperti penginapan dan transportasi.

Wisatawan sering mengalami kesulitan karena media informasi yang minim tentang pariwisata berbasis website. Objek wisata yang terdapat disuatu daerah tidak banyak diketahui atau dikenal oleh wisatawan baik dalam negeri maupun luar negeri sehingga pendapatan daerah dan masyarakat sekitar tidak mengalami peningkatan. Oleh karena itu kebutuhan informasi di bidang pariwisata perlu disiapkan dengan baik, terstruktur dan dapat diakses dengan mudah oleh calon wisatawan.

Informasi merupakan

kumpulan data yang diolah menjadi bentuk yang lebih berguna dan lebih berarti bagi yang menerimanya (Kristanto, 2008 : 92). Informasi adalah data yang diolah menjadi bentuk yang lebih berguna dan lebih berarti bagi yang menerimanaya (Mulyanto, 2009 : 90). Menurut Jogiyanto (2005 : 10) kualitas dari suatu informasi (quality of information) tergantung dari tiga hal, yaitu informasi harus akurat (accurate), tepat pada waktunya (timeliness), dan relevan (relevance).

$$
\text { Kabupaten Sumba Tengah }
$$
merupakan salah satu dari empat kabupaten yang ada di Provinsi Nusa Tenggara Timur dan salah satu daerah di Indonesia yang memiliki sektor pariwisata dan kebudayaan yang menarik. Kabupaten Sumba Tengah memiliki berbagai potensi daya tarik wisata yang digolongkan dalam tiga kelompok besar yaitu daya tarik wisata alam, wisata budaya dan wisata buatan manusia, yang didukung oleh sarana- sarana lain seperti perhotelan, rumah makan dan transportasi.

Potensi daya tarik wisata yang terdata adalah sebanyak 24 buah dengan rincian 14 buah wisata alam, tiga buah wisata budaya, dan tujuh buah wisata buatan manusia dapat dilihat pada Tabel 1. Unggulan Daya tarik wisata antara lain air terjun Matayangu, Pantai Maloba dan Purung ta kadonga (turun ke ladang) dan perkampungan adat yang tersebar di semua kecamatan. Penyebaran informasi tentang tempat pariwisata di Kabupaten Sumba Tengah berbasis 
website masih sangat minim, karena masih bersifat manual seperti pemberian brosur, pamflet, poster dan buku-buku kepada wisatawan yang berkunjung ke suatu objek wisata tersebut:

Tabel 1. Daerah-Daerah Pariwisata Di Kabupaten Sumba Tengah 2014

\begin{tabular}{|c|c|c|}
\hline Kecamatan & Obyek Wisata & Skala Wisatawan \\
\hline 1. Mamboro & $\begin{array}{l}\text { Air terjun Praikalala } \\
\text { Upacara pawolung manu dan tonna usu manua } \\
\text { Pantai karendi } \\
\text { Pantai kapulit } \\
\text { Pantai tarapa }\end{array}$ & $\begin{array}{l}\text { Lokal } \\
\text { Lokal } \\
\text { Lokal dan Internasional } \\
\text { Lokal dan Internasional } \\
\text { Lokal dan Internasional }\end{array}$ \\
\hline 2. Katikutana & $\begin{array}{l}\text { Kampung adat lai tarung dan kabondok } \\
\text { Kampung adat pasunga dan anakalang } \\
\text { Upacara purungu takadonga ratu }\end{array}$ & $\begin{array}{l}\text { Lokal } \\
\text { Lokal } \\
\text { Lokal }\end{array}$ \\
\hline 3.Umbu RatuNggay Barat & $\begin{array}{l}\text { Gua Alam Liangu Marapu } \\
\text { Kampung Adat Kambajawa } \\
\text { Kampung Adat Dewakaworung Anajiaka } \\
\text { Upacara purungu Taliangu Marapu }\end{array}$ & $\begin{array}{l}\text { Lokal } \\
\text { Lokal } \\
\text { Lokal } \\
\text { Lokal }\end{array}$ \\
\hline 4. Umbu RatuNggay & $\begin{array}{l}\text { Air Terjun Wakapori } \\
\text { Gua Alam tana Rara } \\
\text { Kampung Adata Bolu bokat dan marada Date } \\
\text { Pantai Waiurang/Lenang } \\
\text { Pantai pahar/Wende }\end{array}$ & $\begin{array}{l}\text { Lokal } \\
\text { Lokal } \\
\text { Lokal } \\
\text { Lokal dan Internasional } \\
\text { Lokal dan Internasional }\end{array}$ \\
\hline 5. Katikutana Selatan & $\begin{array}{l}\text { Air Terjun Matayangu } \\
\text { Air Terjun Ta urang } \\
\text { Gua Alam liangu paniki } \\
\text { Gua Alam Rati maka Dewa } \\
\text { Kampung Adat Gallu Bakul } \\
\text { Kampung Adat padabar } \\
\text { Pantai Maloba/Aiti }\end{array}$ & $\begin{array}{l}\text { Lokal dan Internasional } \\
\text { Lokal } \\
\text { Lokal } \\
\text { Lokal } \\
\text { Lokal } \\
\text { Lokal } \\
\text { Lokal dan Internasional }\end{array}$ \\
\hline
\end{tabular}

Sumber: Dinas kebudayaan dan Pariwisata Kabupaten Sumba Tengah, 2014

Tabel 1 menunjukan Daerah-daerah pariwisata di Kabupaten Sumba Tengah berdasarkan Kecamatan. Obyek-obyek wisata di Kabupaten Sumba Tengah sebagian besar berskala lokal dan beberapa daerah wisata yang berskala lokal dan luar negeri. Obyek-obyek yang berskala lokal dan luar negeri terdiri atas tujuh obyek wisata yaitu Pantai karendi,
Pantai Kapulit, Pantai Tarapa, Pantai Waiurang/Lenang, Pantai pahar/Wende, Air Terjun Matayangu dan Pantai Maloba/Aiti. Seluruh obyek wisata tersebut adalah wisata alam. Jumlah obyek wisata yang berskala lokal dan luar negeri berjumlah lebih sedikit dari obyek wisata berskala lokal maka diperlukan promosi tentang obyek-obyek wisata 
yang berskala lokal untuk menjadi skala atau Internasional. Salah satu cara mempromosikan obyek-obyek wisata berskala lokal agar dikenalkan secara internasional melalui Website.

Menurut Jogiyanto (2005 : 1) terdapat dua kelompok pendekatan dalam mendefenisikan sistem, yaitu yang menekankan pada prosedurnya dan yang menekankan pada komponen atau elemenya. Pendekatan sistem yang menekankan pada prosedurnya mendefenisikan sistem sebagai berikut: "Sistem adalah suatu jaringan kerja dari prosedur-prosedur yang saling berhubungan, berkumpul bersama-sama untuk melakukan suatu kegiatan atau untuk menyelesaikan suatu sasaran tertentu". Pendekatan sistem yang menekankan pada komponen atau elemennya mendefenisikan sistem sebagai berikut: "sistem adalah kumpulan dari elemen-elemen yang berinteraksi untuk mencapai suatu tujuan tertentu".

Perkembangan teknologi yang semakin pesat seperti internet, sudah saatnya pengelolaan informasi manual secara bertahap diganti dengan pengelolaan informasi yang bersifat teknologi. Untuk itu diperlukan seperti perancangan sistem informasi pariwisata di kabupaten Sumba Tengah. Media internet seperti web, merupakan salah satu alat bantu bagi individu maupun suatu komunitas dalam menjalankan kegiatan kerja. Sistem jaringan yang luas dapat memberikan kemudahan akses informasi yang lebih akurat, cepat dan mudah. Melalui konsep perpaduan teknologi dan pengelolaan pusat informasi pariwisata akan menghasilkan kinerja yang baik bagi pengelola di Kabupaten Sumba Tengah. Selain itu dapat mempermudah penyajian informasi seni kebudayaan dan sarana-sarana yang mendukung seperti perhotelan, rumah makan dan transportasi kepada wisatawan di seluruh dunia.

Berdasarkan penjelasan tentang begitu penting peran informasi pariwisata, maka peneliti tertarik untuk melakukan penelitian yang berkaitan dengan pusat informasi pariwisata di kabupaten Sumba TengahNusa Tenggara Timur, serta memberikan suatu usulan 
rancangan aplikasi informasi pariwisata, yang dapat mempermudah wisatawan untuk berkunjung di kabupaten Sumba Tengah. Selain itu dengan adanya pusat informasi pariwisata berbasis website maka objek-objek wisata dan tempat-tempat yang mendukung pariwisata di daerah Kabupaten SumbaTengah akan lebih dikenal oleh masyarakat luar serta memotivasi pemerintah setempat untuk lebih memperhatikan pengelolaan pada tempat-tempat pariwisata.

\section{METODE}

Penelitian di lakukan oleh peneliti di kabupaten Sumba Tengah, Nusa Tenggara Timur. Peneliti dalam penelitiannya menggunakan dua metode untuk mengumpulkan data, yaitu studi pustaka dan observasi. Data yang diperlukan dalam melakukan penelitian ini yaitu data primer dan data sekunder. Pengumpulan data primer dilakukan dengan cara pengamatan langsung terhadap lokasi pariwisata dan sarana wisata di Kabupaten Sumba Tengah. Pengumpulan data sekunder dengan cara mempelajari dan menelaah dokumen yang berkaitan dengan informasi-informasi pariwisata yang dibutuhkan oleh user yang akan menggunakan sistem informasi ini. Dokumen yang dipelajari dapat bersumber dari buku-buku, referensi internet maupun dari dokumen langsung dari Dinas kebudayaan dan pariwisata Kabupaten Sumba Tengah. Data-data sekunder yang dibutuhkan seperti penginapan, rumah makan dan transportasi. Dalam penyusunan penelitian ini peneliti menggunakan jenis data kualitatif. Metodologi pengembangan sistem yang digunakan dalam penelitian tesis ini menggunakan metode SDLC (System Development Life Cicle) siklus hidup pengembangan sistem, dalam rekayasa sistem dan rekayasa perangkat lunak, adalah proses pembuatan dan pengubahan sistem serta model dan metodologi yang digunakan untuk mengembangkan sistem-sistem tersebut. Konsep ini umumnya merujuk pada informasi. Dalam rekayasa perangkat lunak, konsep SDLC mendasari berbagai jenis metodologi pengembangan perangkat lunak. Metodologi- 
metodologi ini membentuk suatu kerangka kerja untuk perencanaan dan pengendalian pembuatan sistem informasi, yaitu proses pengembangan perangkat lunak. Model yang dipakai peneliti meliputi: 1) Perencanaan Sistem, 2) Analisa Sistem, 3) Perancangan (Design) sistem, 4) Implementasi Sistem dan 5) Pengujian (Testing) Sistem.

\section{HASIL DAN PEMBAHASAN}

\section{A. Perancangan Interface}

1. Rancangan Layar Home

Rancangan menu utama atau Home adalah menu pembuka yang berisi tentang kabupaten Sumba Tengah, Galery, dan informasi tourism.

2. Rancangan layar Tourism Info Rancangan layar Tourism Info berisi tentang informasiinformasi wisata yang ada di Kabupaten Sumba Tengah seperti wisata alam, wisata budaya, kuliner, upacara tradisional, tarian tradisional dan wisata buatan.

3. Rancangan Layar Services Rancangan layar services berisi tentang info Hotel, info rumah makan dan info travel yang ada di kabupaten Sumba Tengah.

4. Rancangan Layar Tours Rancangan layar Tours berisi tentang perjalanan yang dilakukan untuk wisatawan dalam memilih Hotel, rumah makan, dan travel yang ada di kabupaten Sumba Tengah sesuai dengan keuangan yang ada.

5. Rancangan Layar Gallery

Rancangan Layar Gallery berisi tentang gambar-gambar objek wisata alam, objek wisata budaya dan objek wisata buatan yang terdapat di Kabupaten Sumba Tengah.

6. Rancangan Layar Map Rancangan Layar Map berisi tentang peta Kabupaten Sumba Tengah agar wisatawan lebih muda dalam mencari lokasi yang ingin dikunjungi.

7. Rancangan Layar Contact Rancangan menu contact berisi tentang peta, jointlink 
facebook, joint linktwitter, dan pesan.

8. Rancangan Layar AdminLogin

Menu admin berisi tentang Username dan password, jika username dan pasword yang kita masukan benar atau sesuai maka kita berhak mengunah data yang ada.

9. Rancangan Layar Admin Tulisan

Menu Admin - Tulisan berisi tentang tulisan - tulisan apa saja yang ingin dimasukan dalam laman web.

10. Rancangan Layar Admin Media

Menu Admin - Media berisi tentang gambar dan video yang dimasukan dalam laman web.

11. Rancangan layar Admin Halaman

12. Menu Admin

Halaman berisi tentang halaman atau konten apa saja yang dimasukan dalam laman web.

13. Rancangan Layar Admin Komentar
Menu admin - komentar berisi tentang komentar dari pengunjung web baik saran maupun kritik dan dimasukan dalam laman web.

14. Rancangan Layar Admin Tours

Menu Admin - Tours berisi tentang pelayanan yang ada di Kabupaten Sumba Tengah seperti info travel, info Hotel dan Restoran.

15. Rancangan Layar Admin Galleries

Menu admin - Galleries berisi tentang gambar ataupun video yang ada pada website seperti gambar wisata alam, wisata budaya, wisata buatan dan tarian adat.

16. Rancangan Layar admin Slide

Menu Admin - Slide berisi tentang slide yang ada pada layar home.

\section{B. Perancangan Struktur Tampilan}

Untuk perancangan struktur tampilan alat yang digunakan adalah state Transition Diagram (STD). STD digunakan untuk menggambarkan urutan dan variasi tampilan dari 
aplikasi Sumba Tengah Tourism Center.

sebagai

berikut:

STD dari aplikasi tersebut adalah

1. STD dari Menu Home - Tours

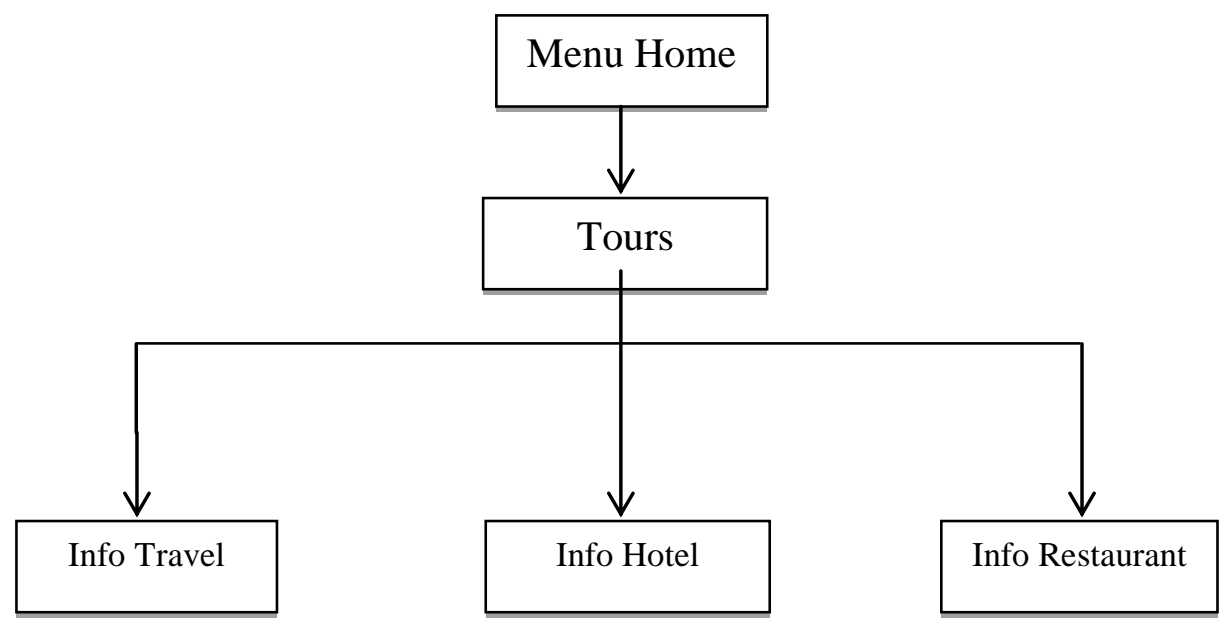

Gambar 1. STD Menu Home - Tours

Keterangan :

1. Home adalah halaman muka dari suatu situs web (website), atau lokasi dari situs web di mana dokumen web dapat diakses.

2. Tours dalam website ini adalah informasi berupa akomodasi perjalanan wisata yang ada di Kabupaten Sumba Tengah, terdiri dari : a. Info travel merupakan info jasa transportasi yang ada di Kabupaten Sumba Tengah.

b. Info Hotel merupakan info jasa penginapan yang ada di Kabupaten Sumba Tengah.

c. Info Restaurant merupakan info rumah makan yang ada di Kabupaten Sumba Tengah.

2. STD dari Menu Home - Tourist Info 


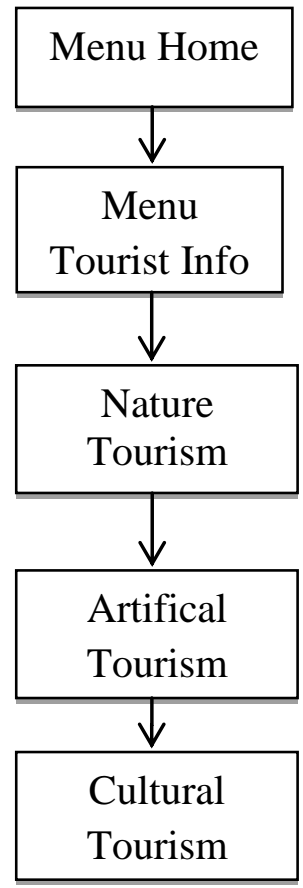

Gambar 2. STD Menu Home - Tourist Info

Keterangan :

1. Homeadalah halaman muka dari suatu situs web (website), atau lokasi dari situs web di mana dokumen web dapat diakses.

2. Tourist Info adalah info wisatawisata yang ada di kabupaten Sumba Tengah yang dibagi menjadi tiga bagian :

a. Nature Tourism adalah Info wisata alam yang ada di Kabupaten Sumba Tengah, seperti pantai Maloba, pantai Konda dan Air terjun Matayangu.

b. Artifical Tourism adalah Info wisata buatan manusia yang ada di Kabupaten Sumba tengah, seperti kuburan batu megalitik yang ada di kampung pasunga.

c. Cultural Tourism adalah Info wisata budaya Kabupaten Sumba Tengah, seperti rumah adat Deri Kambajawa, Ritual Adat, dan Tarian tradisonal.

\section{Implementasi}

Pada tahap Implementasi aplikasi pengembangan sistem informasi Sumba Tengah Tourism Center berbasis web diperlukan update data seperti update data hotel, data rumah makan dan data-data tempat wisata yang ada di Kabupaten Sumba 
Tengah, yang sewaktu-waktu dapat bertambah ataupun berkurang.

\section{KESIMPULAN}

Pariwisata merupakan salah satu sektor yang dapat menghasilkan pendapatan yang luar biasa bagi suatu daerah terutama apabila dikelola dengan baik. Tetapi pengelolaan yang baik tidak akan berjalan sesuai dengan tujuan awal tanpa adanya berbagai dukungan yang melatar belakangi pengelolaan tersebut. Salah satu sarana pendukung yang dimaksud adalah dengan adanya sebuah sistem informasi pariwisata yang diharapkan bisa memenuhi kebutuhan pengguna akan informasi pariwisata suatu daerah tujuan wisata, selain itu juga dapat digunakan sebagai media promosi daerah tersebut dalam mempromosikan pariwisatanya. Dari hasil pembahasan yang telah dijelaskan maka penulis mengambil kesimpulan diantaranya :

1. Hasil penelitian menunjukan dengan menggunakan sistem informasi berbasis web dapat membantu kelancaran kegiatan pariwisata di Kabupaten Sumba
Tengah serta dapat memperluas jangkaun untuk menyampaikan informasi pariwisata dibandingkan dengan menggunakan sistem manual.

2. Sistem informasi pariwisata yang telah dirancang ini dapat memberikan informasi mengenai data pariwisata dan seni budaya Kabupaten Sumba Tengah yang selalu di update.

3. Website ini dapat membantu mempromosikan Pariwisata Kabupaten Sumba Tengah kepada seluruh masyarakat di Tanah air Indonesia bahkan masyarakat Internasional.

\section{DAFTAR PUSTAKA}

Demarco, Tom, 1978, Structured Analysis And System Specification, Yourdon

Fathansyah, 1999, Basis Data, Penerbit Informatika, Bandung

Firdaus, 2007, 7 Jam Belajar Interaktif PHP \& Mysql Dengan Dreamweaver, Palembang, Maxikom

Fuadi, Ali, 2013, Perancangan Dan Pembuatan Sistem Informasi Pariwisata Kabupaten Simelue Berbasis Web, Universitas Budiyah Indonesia 
Gordon, Davis, 1991, Sistem Informasi Manajemen, PT. Gramedia, Jakarta.

Jogiyanto, H.M, 2005, Analisis Dan Desain, Andi Offset, Yogyakarta.

Jogiyanto, H.M, 2008, Sistem Teknologi Informasi, Andi, Yogyakarta.

Kadir, Abdul, 2002, Pengenalan Sistem Informasi, Andi, Offset, Yogyakarta.

Kadir, Abdul, 2003, Konsep Dan Tuntunan Praktis Basis Data, Andi, Yogyakarta.

Karyono, Hary, 1997, Kepariwisataan. Grasindo, Jakarta.

Kendall, 2006, System Analys And Design,New Jersey, Person Education, Inc. Upper Saddle River.

Kristianto, Andri, 2008, Perancangan Sistem Informasi Dan Aplikasinya, Gava Media, Yogyakarta
Mustakini, 2009, Sistem Informasi Teknologi, Andi, Yogyakarta.

Mulyanto, 2009, Sistem Informasi Konsep Dan Aplikasi, Pustaka Pelajar, Yogyakarta.

Oetomo, Budi, 2007, E-Education : Konsep Teknologi Dan Aplikasi Internet Pendidikan. Andi Offset, Yogyakarta.

Sutabri, Tata, 2012, Konsep Sistem Informasi, Andi, Yogyakarta.

Pendit, I Nyoman, 1994, Ilmu Pariwisata Sebuah Pengantar Perdana, Pradnya Paramita, Jakarta.

Sidik, Betha, 2006, Pemprograman WEB Dengan PHP, Informatika, Bandung

Soekadijo, 2000, Anatomi Pariwisata, Gramedia, Jakarta.

Yakub, 2012, Pengantar Sistem Informasi, Graha Ilmu, Yogyakarta. 